\title{
Sex Steroid Regulation of the Inflammatory Response: Sympathoadrenal Dependence in the Female Rat
}

\author{
Paul G. Green, ${ }^{1,4}$ Solbritt Rantapää Dahlqvist, ${ }^{5}$ William M. Isenberg, ${ }^{2,4}$ Holly J. Strausbaugh, ${ }^{1,4}$ \\ Frederick J.-P. Miao, ${ }^{1,4}$ and Jon D. Levine ${ }^{1,3,4}$ \\ Departments of ${ }^{1}$ Oral and Maxillofacial Surgery, ${ }^{2}$ Obstetrics Gynecology and Reproductive Sciences and ${ }^{3}$ Medicine, \\ ${ }^{4}$ Division of Neuroscience and National Institutes of Health Pain Center (UCSF), University of California San Francisco, \\ San Francisco, California 94143-0440, and 5Department of Rheumatology, Umeå University Hospital, \\ SE-901 85, Sweden
}

To investigate the role of sex steroids in sex differences in the response of rats to the potent inflammatory mediator bradykinin (BK), we evaluated the effect of sex steroid manipulation on the magnitude of BK-induced synovial plasma extravasation (PE). The magnitude of BK-induced PE is markedly less in females. Ovariectomy of female rats increased BK-induced PE, and administration of $17 \beta$-estradiol to ovariectomized female rats reconstituted the female phenotype. Castration in male rats decreased BK-induced PE, and administration of testosterone or its nonmetabolizable analog dihydrotestosterone reconstituted the male phenotype. The results of these experiments strongly support the role of both male and female sex steroids in sex differences in the inflammatory response.

Because the stress axes are sexually dimorphic and are important in the regulation of the inflammatory response, we evaluated the contribution of the hypothalamic-pituitaryadrenal and the sympathoadrenal axes to sex differences in
BK-induced PE. Neither hypophysectomy nor inhibition of corticosteroid synthesis affected BK-induced PE in female or male rats. Adrenal denervation in females produced the same magnitude increase in BK-induced PE as adrenalectomy or ovariectomy, suggesting that the adrenal medullary factor(s) in females may account for the female sex steroid effect on BK-induced PE. Furthermore, we have demonstrated that in female but not male rats, estrogen receptor $\alpha$ immunoreactivity is present on medullary but not cortical cells in the adrenal gland. These data suggest that regulation of the inflammatory response by female sex steroids is strongly dependent on the sympathoadrenal axis, possibly by its action on estrogen receptors on adrenal medullary cells.

Key words: plasma extravasation; inflammation; sex differences; estrogen; testosterone; estrogen receptor; sympathoadrenal axis; hypothalamic-pituitary adrenal axis
Most inflammatory rheumatic diseases (e.g., rheumatoid arthritis and systemic lupus erythmatosus) are more common in women (Da Silva, 1995). In addition, severity of rheumatoid arthritis (Deighton et al., 1992; Katz and Criswell, 1996), in particular joint destruction (Weyand et al., 1998), is greater in women. In animal models of inflammatory disease, similar sex differences have been reported; for example, in rodents, the susceptibility to and severity of experimental arthritis is greater in females (MacKenzie et al., 1979; Wilder et al., 1982; Allen et al., 1983; Griffiths et al., 1994; Holmdahl, 1995). Research in both humans and animals has implicated a role of sex steroids in susceptibility to and severity of inflammatory rheumatic diseases (Da Silva et al., 1994; Jemec and Heidenheim, 1995; Josefsson and Tarkowski, 1997). For example, sex differences in the severity of experimental arthritis (number of joints involved, degree of erythema, and swelling) are abolished in male rats following either castration or administration of the principal female sex steroid $17 \beta$-estradiol (Allen et al., 1983).

Stress may also contribute to severity of arthritis because the

Received Sept. 22, 1998; revised Feb. 19, 1999; accepted Feb. 24, 1999.

This work was supported by National Institutes of Health Grant NR12773. We thank Professor Mary Dallman for her many helpf ul comments during the course of these experiments.

Correspondence should be addressed to Dr. Paul G. Green, NIH/UCSF Pain Center, C-522, Box 0440, University of California San Francisco, San Francisco, CA 94143-0440.

Copyright (C) 1997 Society for Neuroscience 0270-6474/97/194082-08\$05.00/0 sympathoadrenal axis modulates the inflammatory response $\left(\alpha_{2}-\right.$ adrenergic receptor activation decreases severity whereas $\beta_{2}$ adrenergic activity increases severity in models of chronic inflammation) (Coderre et al., 1990, 1991; Miao et al., 1992a; Lundeberg et al., 1993). Of note, the sympathetic and sympathoadrenal stress axes are sexually dimorphic; for example, female rats exhibit higher basal (DeTurck and Vogel, 1980) and stimulated (Livezey et al., 1985; Taylor et al., 1989) plasma epinephrine and norepinephrine levels, muscle sympathetic nerve activity (burst frequency and burst incidence) is higher in women ( $\mathrm{Ng}$ et al., 1993), and stress-induced increases in plasma norepinephrine in men are enhanced by estradiol treatment (Kirschbaum et al., 1996). In addition, androgens also modulate sympathoadrenal activity in male rats (Le Thu et al., 1984) and men (Del Rio et al., 1995). Interestingly, although epinephrine acts via $\beta_{2}$-adrenergic receptors to inhibit synovial plasma extravasation, it also produces, by the same mechanism, exacerbation of joint damage in complete Freund's adjuvant-induced arthritis in rats (assessed radiographically) (Coderre et al., 1990, 1991). This inverse relationship between magnitude of synovial plasma extravasation and severity of experimental arthritis occurs with other pharmacological interventions (Green et al., 1991; Miao et al., 1992b), indicating that the net effect of increasing plasma extravasation is to contribute to tissue repair/protection rather than tissue injury. In fact, recently it has been noted that physiological control of inflammation occurring after local generation of bradykinin (BK) 
to enhance vascular permeability may be caused by the increased extravasation of plasma proteinase inhibitors (e.g., $\alpha_{1}$-proteinase inhibitor, $\alpha_{1}$-anti-chymotrypsin, and $\alpha_{2}$-macroglobulin). These mediators control excessive proteolytic activity and thereby protect against connective tissue damage (Kozik et al., 1998).

The hypothalamic-pituitary-adrenal (HPA) axis, which also plays an important role in modulating the inflammatory response (Sternberg et al., 1989; Sweep et al., 1991; Calogero et al., 1992), is also sexually dimorphic in both animals and humans (Da Silva, 1995). For example, (1) testosterone tends to inhibit HPA axis function, whereas estrogen enhances HPA function (Handa et al., 1994; Suescun et al., 1994), (2) female rats have a higher basal plasma corticosterone level than males (Kitay, 1961; Ehlers et al., 1993) and a greater stress response (for review, see Da Silva, 1995), and (3) in humans there is a greater HPA axis stress response in females (Peskind et al., 1995). It has been hypothesized that the apparent paradox of a both greater arthritic severity/incidence and higher glucocorticoid levels in females is attributable to females being more dependent on glucocorticoids than males to modulate inflammation (Da Silva, 1995).

In this study we have tested the hypothesis that sex differences in magnitude of a critical component of the inflammatory response (i.e., inflammatory mediator-induced plasma protein extravasation) is dependent on sex steroids and that the effect of female sex steroids is mediated through the sympathoadrenal and/or the HPA axes.

We present evidence that $17 \beta$-estradiol suppresses and testosterone enhances inflammatory mediator-induced plasma extravasation (PE), and that the effect of $17 \beta$-estradiol is sympathoadrenal axis-dependent.

\section{MATERIALS AND METHODS}

\section{Animals}

The experiments were performed on weight-matched male and female Sprague Dawley rats (Bantin and Kingman, Fremont, CA, except as described below). Rats were used in PE experiments when they weighed 280-380 gm. The rats were housed in a temperature- and humiditycontrolled environment and were maintained on a $12 \mathrm{hr}$ light/dark cycle (lights on at 6 A.M.). Food and water were available ad libitum. Experiments were approved by the UCSF Committee on Animal Research.

\section{Plasma extravasation}

BK-induced plasma extravasation in the knee joint of the rat was assessed as described previously (Coderre et al., 1989; Green et al., 1991). Rats were anesthetized with sodium pentobarbital (Nembutal, $50 \mathrm{mg} /$ $\mathrm{kg}$ ). Skin overlying the knee was excised to expose the joint capsule, and rats were then given an intravenous injection of Evans blue dye (50 $\mathrm{mg} / \mathrm{kg}$, in a volume of $2.5 \mathrm{ml} / \mathrm{kg}$ ). A 30 gauge hypodermic needle was then inserted into the knee joint cavity for the inflow of perfusion fluid $(250 \mu \mathrm{l} / \mathrm{min}$; controlled by a syringe pump, Sage Instruments model $341 \mathrm{~B})$, and after infusion of 100-200 $\mu \mathrm{l}$ of fluid, a second needle (25 gauge) was inserted into the joint cavity for outflow of the perfusion fluid (250 $\mu \mathrm{l} / \mathrm{min}$; syringe pump, Sage Instruments model 351). Samples of perf usion fluid were collected over $5 \mathrm{~min}$ intervals for a period of $90 \mathrm{~min}$. Samples were analyzed for Evans blue dye concentration by spectrophotometric measurement of absorbance at $620 \mathrm{~nm}$; absorbance is linearly related to dye concentration (Carr and Wilhelm, 1964). After collection of the first three samples (to establish baseline plasma extravasation levels), BK (150 nM) was added to the perfusing fluid and remained present in the fluid for the duration of the experiment.

\section{Gonadectomy}

Gonadectomy was performed on male and female rats at 3 weeks of age, i.e., before onset of puberty, and animals were used in plasma extravasation experiments when they weighed $280-380 \mathrm{gm}$.

Oophorectomy. Under brief ether anesthesia, a single cutaneous incision was made along the dorsal midline followed by bilateral incisions through the peritoneum. The ovaries were located, and their vascular bundles were tied off with 4-0 silk suture. Ovaries were then excised, and the cutaneous incision was closed with 5-0 silk suture (Waynforth and Flecknell, 1992)

Orchiectomy. Under brief ether anesthesia, a single cutaneous incision was made through the scrotal skin, and the peritoneal cavity was entered to expose the testes. The vascular bundles were tied off with 4-0 silk suture, and the testes were then removed. The cutaneous incision was closed with 5-0 silk suture (Waynforth and Flecknell, 1992).

\section{Administration of sex steroids}

Chronic administration of sex steroids was performed as described previously (Smith et al., 1977). Briefly, 17- $\beta$-estradiol and testosterone were administered via implanted SILASTIC tubes. Segments of SILASTIC tubing $(1.67 \mathrm{~mm}$ inner diameter $\times 3.18 \mathrm{~mm}$ outer diameter $)$ were used to make hormone implants as follows: testosterone implants consisted of 30-mm-long segments filled with testosterone, and estrogen implants consisted of 10 -mm-long segments filled with $17 \beta$-estradiol. Sham implants were prepared of each length and filled with cholesterol. The ends of the implants were capped with wooden plugs and sealed with SILASTIC medical adhesive (Dow Corning, Midland, MI). Implants were washed in absolute ethanol and equilibrated in four changes of warm PBS over a $24 \mathrm{hr}$ period before placement in the rat. Implants, which were placed subcutaneously at the time of gonadectomy, produce physiological levels of sex steroids (Bridges and Russell, 1981; Bridges, 1984).

\section{Adrenalectomy}

To remove both adrenal glands, rats were anesthetized with pentobarbital. Incisions in the abdominal wall were made to expose the adrenal glands, which were then excised. Adrenalectomy was performed 1 week before PE experiments. During that week, the rats' drinking water contained $0.5 \%$ sodium chloride and $25 \mu \mathrm{g} / \mathrm{ml}$ corticosterone; water was removed $1 \mathrm{hr}$ before animals were used in PE studies. To confirm that adrenalectomies were complete, immediately before being used in PE studies, corticosterone levels were assessed as described below and shown to be $<1 \mu \mathrm{g} / \mathrm{dl}$.

\section{Adrenal denervation}

The greater splanchnic nerve innervating the adrenal gland was exposed after a lateral incision was made in the abdominal wall; the adrenal innervation region was isolated close to the adrenal gland and cut, as described previously (Celler and Schramm, 1981). Joint perfusion experiments were carried out at least $7 \mathrm{~d}$ after adrenal denervation. Bilateral adrenal denervation did not affect the baseline level of BKinduced plasma extravasation (data not shown). To ensure that adrenal denervation did not interfere with the function of the adrenal cortex, plasma samples were collected immediately after induction of anesthesia for knee joint perfusion experiments and assayed for corticosterone levels as described below.

\section{Hypophysectomy}

Hypophysectomized Sprague Dawley rats were purchased from Charles River (Hollister, CA). Hypophysectomies were performed after ventral midline incision was made through the mandible to expose the ventral surface of the cranium. Trephines were used to excise a section of cranium and expose the hypophysis, which was then aspirated. For the first week after surgery, animals were given 5\% sucrose in their drinking water, and animals were used in PE studies 7-10 d after hypophysectomy. Intact rats from Charles River, which produce the same degree of BK-induced PE as those from Bantin and Kingman (Green et al., 1995), were used as control animals.

\section{Corticosterone assay}

Blood samples (50-100 $\mu \mathrm{l}$ ) were collected from pentobarbital-anesthetized animals by venipuncture (tail vein) immediately before the knee joint perfusion experiment. Samples were immediately centrifuged, and plasma was taken and stored at $-20^{\circ} \mathrm{C}$ until assayed.

Total plasma corticosterone was assayed with a double antibody ${ }^{125} \mathrm{I}$ RIA kit (ICN Biomedicals, Costa Mesa, CA) as described previously (Akana et al., 1985). The assay has a sensitivity of detection of $0.5 \mu \mathrm{g} / \mathrm{ml}$ and has a cross-reactivity reported by ICN Biomedicals as $0.34 \%$ for desoxycorticosterone and $0.1 \%$ for testosterone.

\section{Estrogen receptor $\alpha$ immunocytochemistry}

Adrenal glands were excised from anesthetized male and female animals and immersed in Zamboni's fixative for $4 \mathrm{hr}$ at $25^{\circ} \mathrm{C}$. Tissue blocks were 
dehydrated, infiltrated, and embedded in paraffin. Histologic sections were prepared at a thickness of $5 \mu \mathrm{m}$ and collected on glass slides. The sections were processed for estrogen receptor $\alpha$ immunocytochemistry using the Dako estrogen receptor $\alpha$-labeled streptavidin-biotin kit (Dako Labs, Carpinteria, CA) following the manufacturer's instructions. Briefly, slides were deparaffinized, rehydrated, and incubated in Dako Target Retrieval Solution. After rinsing, the slides were treated with 3\% aqueous hydrogen peroxide to quench endogenous peroxidase activity, rinsed, and exposed to either 1D5 primary antibody or an isotypically matched mouse IgG1 control reagent. The 1D5 monoclonal antibody is a very well characterized reagent, shown to bind to estrogen receptor $\alpha$ in human endometrial and myometrial cells and normal and hyperplastic mammary epithelial cells, as well as some breast carcinoma epithelia. Similarly, this reagent has been used to identify estrogen receptor $\alpha$-containing cells in neurons, uteri, and growth plates of rats (Greco et al., 1998; Kennedy et al., 1999). After rinsing, the slides were sequentially exposed to biotinylated anti-mouse immunoglobulins, streptavidin conjugated to horseradish peroxidase, and 3,3'-diaminobenzidine chromogen in imidazole- $\mathrm{HCl}$, containing hydrogen peroxide. Hematoxylin counterstain was not used to avoid obscuring nuclear estrogen receptor reactivity. The slides were rinsed and coverslipped in AquaMount. Slides from different experimental groups were reacted at the same time. Because this reagent kit is used by the UCSF diagnostic pathology laboratory, the reagents are tested at least once per week on a human breast tumor with demonstrated estrogen receptor $\alpha$ activity. Slides were viewed with a Nikon Microphot-FXA and photographed with a Sony DKC-5000 digital camera.

\section{Materials}

Evans blue dye, bradykinin triacetate, $17 \beta$-estradiol, testosterone, dihydrotestosterone, and metyrapone were obtained from Sigma (St. Louis, MO). SILASTIC tubing (Dow Corning, Midland, MI) was obtained from Storz Instrument Company (St. Louis, MO). Nembutal was obtained from Abbott Laboratories (North Chicago, IL). Anti-estrogen receptor $\alpha$ antibody was obtained from Dako Labs. Testosterone and $17 \beta$-estradiol were used in crystalline form, metyrapone was dissolved in DMSO, and all other drugs were dissolved in $0.9 \%$ saline.

\section{Statistical analysis}

Plasma extravasation data were analyzed using repeated-measures ANOVA with one between-subjects factor, treatment, with two levels (control and treated) and one within-subjects factor, time, with 10 levels (20-90 min, 5 min intervals). We present the results of the analysis of the main effect and treatment group. Fisher's least squares difference test (Fisher, 1949) was used for post hoc comparisons. Differences were considered significant when $p<0.05$.

\section{RESULTS}

\section{Plasma extravasation}

Effects of sex

Perfusion of the knee joint with BK produced a sustained increase in PE that reached a plateau within 25-30 min in both male and female rats. The magnitude of BK-induced $\mathrm{PE}$ in female rats was $\sim 50 \%$ of that produced in males $(p<0.05)$ (Fig. 1).

\section{Females}

We addressed the question of whether $17 \beta$-estradiol decreased, and testosterone increased, BK-induced PE in female rats.

Effects of gonadectomy. To determine the role of female sex steroids in sex differences in BK-induced PE, rats were ovariectomized. After ovariectomy, the magnitude of BK-induced PE was significantly higher than that produced in intact females $(p<$ 0.05) (Fig. 2).

Effects of hormone administration. To determine whether the difference in magnitude of BK-induced PE after ovariectomy can be reversed by replacement with a single hormone, we evaluated the effect of chronic exposure to $17 \beta$-estradiol in ovariectomized female rats. $\mathrm{BK}$-induced $\mathrm{PE}$ in ovariectomized rats with $17 \beta$ estradiol implants was significantly lower than after ovariectomy alone and not significantly different from that seen in intact

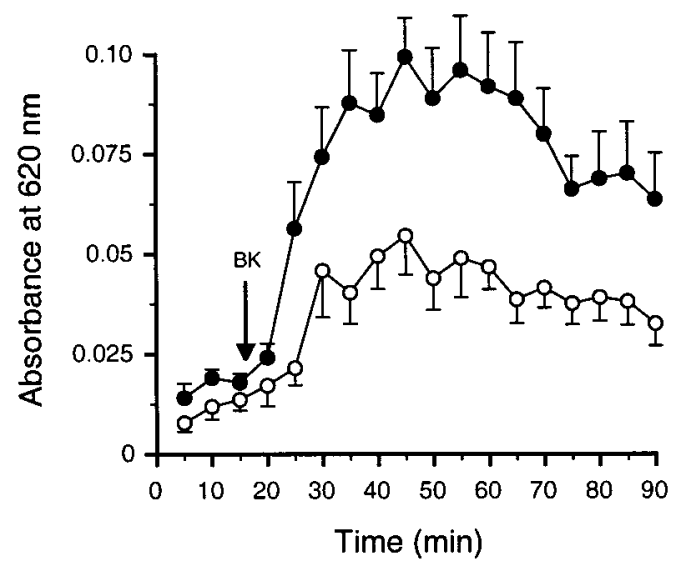

Figure 1. BK-induced PE in male and female rat knee joints. After establishment of baseline PE in the first three samples, BK (150 nM) was added to the perfusion fluid and was perfused continuously for the remainder of the experiment. BK was perfused through the knee joints of both male $(\bullet, n=13)$ and female $(\bigcirc, n=13)$ rats; the magnitude of PE was greater in the knee joint of male rats. In this and subsequent figures, data are presented as mean \pm SEM of $n$ values, and ordinate is absorbance of light at $620 \mathrm{~nm}$, which is linearly proportional to the concentration of Evans blue dye (Carr and Wilhelm, 1964).

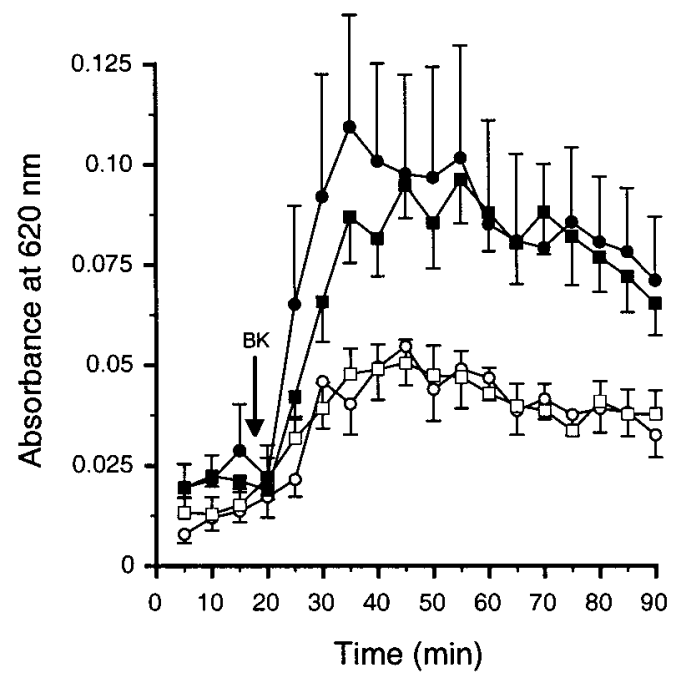

Figure 2. Effect of gonadectomy and sex steroid administration on BKinduced PE in female rat knee joints. The magnitude of BK-induced PE in adult female rats ovariectomized at $21 \mathrm{~d}$ of age either without sex steroid implants $(\boldsymbol{\square}, n=12)$ or with testosterone implants $(\boldsymbol{\bullet}, n=7)$ was significantly greater than that produced in weight-matched controls $(\bigcirc$, $n=13$ ). The magnitude of BK-induced PE in ovariectomized rats with $17 \beta$-estradiol implants $(\square, n=10)$ was not significantly different from that seen in weight-matched controls.

females ( $p>0.05)$ (Fig. 2). In contrast, ovariectomized females implanted with testosterone had a BK-induced PE not significantly different from that produced by ovariectomy alone.

We next addressed the question of whether female sex steroid effects on BK-induced PE were sympathoadrenal or HPA axis dependent.

Effect of lesions of sympathoadrenal axis. We found that adrenal denervation also resulted in BK-induced PE that was significantly higher than that produced in intact female rats $(p<0.05)$ (Fig. $3 A$ ). Similarly, BK-induced $\mathrm{PE}$ in adrenal denervation in ovariectomized estrogen-replaced rats was higher than in intact fe- 


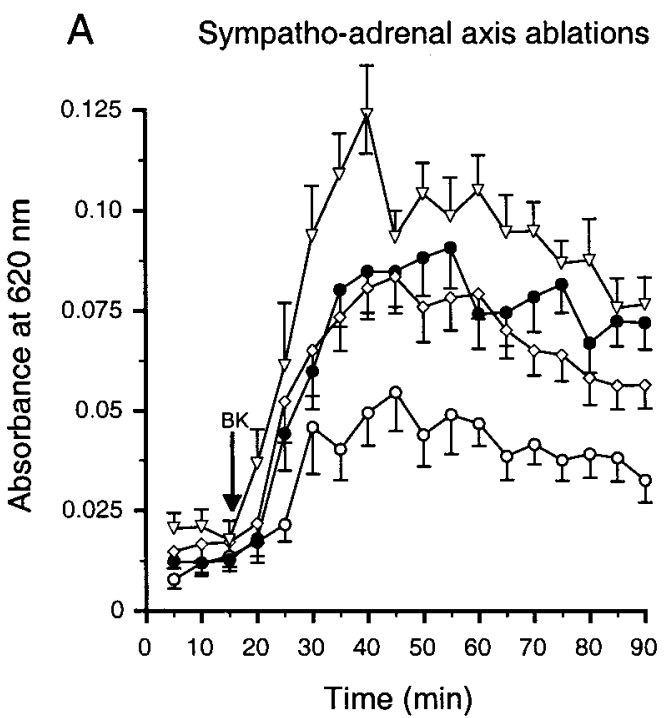

males $(p<0.05)$ (Fig. $3 A)$ and not significantly different from that produced by adrenal denervation alone. Plasma corticosterone levels were not significantly different in adrenal-denervated rats $(34.5 \pm 4.9 \mu \mathrm{g} / \mathrm{dl})$ compared with pentobarbital-anesthetized controls $(39.2 \pm 3.5 \mu \mathrm{g} / \mathrm{dl})$. Sham surgeries did not affect BKinduced PE (data not shown).

Effect of lesions of HPA axis. In female rats, surgical hypophysectomy (to evaluate the pituitary contribution) and metyraponeinduced inhibition of glucocorticoid synthesis (to evaluate the adrenal cortical contribution) did not significantly alter the magnitude of BK-induced PE $(p>0.05)$ (Fig. $3 B)$. However, adrenalectomy that interrupts the sympathoadrenal axis as well, significantly increased BK-induced PE $(p<0.05)$ (Fig. $3 A)$. Plasma corticosterone levels in all adrenalectomized animals were $<1$ $\mu \mathrm{g} / \mathrm{dl}$. Plasma corticosterone levels were also reduced after hypophysectomy $(0.9 \pm 0.3 \mu \mathrm{g} / \mathrm{dl})$ and metyrapone treatment $(1.2 \pm$ $0.4 \mu \mathrm{g} / \mathrm{dl})$ compared with control pentobarbital-anesthetized females $(39.2 \pm 3.5 \mu \mathrm{g} / \mathrm{dl})$. Sham adrenalectomies did not affect BK-induced PE (data not shown).

\section{Males}

We next addressed the question of whether testosterone and dihydrotestosterone raise and $17 \beta$-estradiol decreases levels of BK-induced PE in male rats.

Effects of gonadectomy. After castration in male rats, BKinduced PE was significantly less than that produced in intact controls $(p<0.05)$ (Fig. 4).

Effects of hormone administration. We evaluated the effect of chronic exposure to testosterone and dihydrotestosterone in castrated male rats. BK-induced $\mathrm{PE}$ in gonadectomized testosteronetreated and gonadectomized dihydrotestosterone-treated males was not significantly different from that produced in intact males $(p>0.05)$ (Fig. 4). In contrast, gonadectomized males implanted with $17 \beta$-estradiol had a BK-induced PE not significantly different from that produced in males that were only gonadectomized.

Finally, we addressed the question of whether male sex steroid effects on BK-induced PE were HPA or sympathoadrenal axis dependent.

Effect of lesions of sympathoadrenal axis. Sympathoadrenal axis ablation (adrenal denervation) in males had no effect on the magnitude of BK-induced PE compared with intact males $(p>$ 0.05 ) (Fig. 5A). Plasma corticosterone levels after adrenal dener-
HPA axis ablations

Figure 3. Effect of HPA or sympathoadrenal axis lesions on BK-induced PE produced in female rat knee joints. $A$, Sympathoadrenal axis. Both adrenalectomy $(\bullet, n=18)$ and adrenal denervation $(\diamond, n=14)$ significantly enhanced BK-induced PE compared with control females $(\bigcirc, n=13)$. Adrenal denervation also enhanced BK-induced $\mathrm{PE}$ in ovariectomized rats receiving $17 \beta$ estradiol $(\nabla, n=7)$. $B$, HPA axis. BKinduced PE in hypophysectomized $(\square$, $n=10)$ and metyrapone-treated female rats $(\triangle, n=9)$ was not significantly different from that produced in control females $(\bigcirc, n=13)$. However, BKinduced $\mathrm{PE}$ in adrenalectomized $(\bullet, n=$ 18) female rats was significantly greater than in control females.
Time $(\min )$

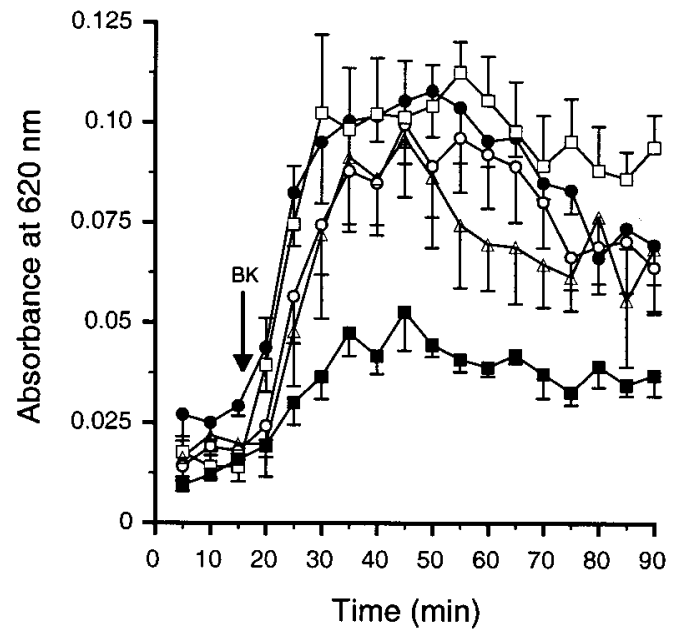

Figure 4. Effect of gonadectomy and sex steroid administration on BKinduced PE in male rat knee joints. The magnitude of BK-induced PE in adult male rats castrated at $21 \mathrm{~d}$ of age and chronically receiving either dihydrotestosterone $(\bullet, n=6)$, DHT $(\square, n=8)$, or $17 \beta$-estradiol $(\triangle, n=$ 7) was not significantly different from that produced in weight-matched controls $(\bigcirc, n=13)$, but was significantly greater than the magnitude of BK-induced PE produced in castrated $(\mathbf{\square}, n=9)$ male rats.

vation $(13.3 \pm 3.0 \mu \mathrm{g} / \mathrm{dl})$ were not significantly different from those from control males $(21.2 \pm 2.6 \mu \mathrm{g} / \mathrm{dl})$.

Effect of lesions of HPA axis. In male rats, after lesions of the HPA axis (i.e., hypophysectomy, adrenalectomy, or metyrapone treatment) BK-induced PE was not significantly different from that produced in intact rats $(p>0.05)$ (Figs. $5 B)$. Plasma corticosterone in all adrenalectomized animals was $<1 \mu \mathrm{g} / \mathrm{dl}$.

\section{Estrogen receptor $\alpha$ immunohistochemistry}

Immunoreactivity for estrogen receptor $\alpha$ was evident in the cytoplasm of adrenal medullary cells in female rats (Fig. 6). No estrogen receptor $\alpha$ immunoreactivity was apparent in adrenal cortical cells. No estrogen receptor $\alpha$ immunoreactivity was apparent in adrenal medullary or cortical cells of male rats (data not shown).

\section{DISCUSSION}

In this study we have shown that PE produced by the potent inflammatory mediator BK is markedly lower in female compared 
Figure 5. Effect of HPA or sympathoadrenal axis lesions on BK-induced PE produced in male rats. $A$, Sympathoadrenal axis. BK-induced PE in adrenalectomized $(\bullet, n=18)$ and adrenaldenervated $(\diamond, n=14)$ male rats was not significantly different from that produced in control males $(\bigcirc, n=13)$. $B$, HPA axis. BK-induced PE in adrenalectomized $(\mathbf{\bullet}, n=11)$, hypophysectomized $(\square, n=5)$, and metyrapone-treated male rats $(\triangle, n=9)$ was not significantly different from that produced in control males $(\bigcirc, n=13)$.
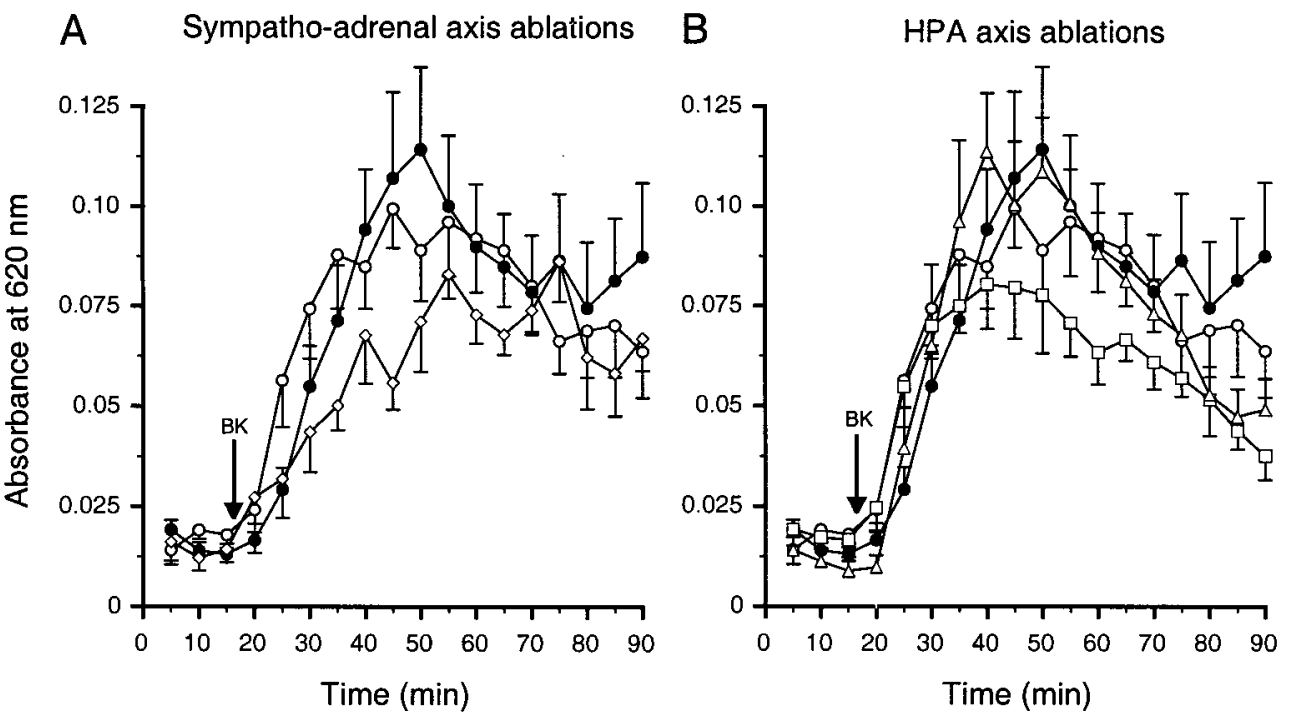

with male rats. This gender difference can be accounted for in part by female and male sex steroids. The contribution of the female sex steroid $17 \beta$-estradiol is, at least in part, sympathoadrenal axis dependent.

\section{Plasma extravasation}

\section{Influence of sex steroids}

Because reports in the literature have shown that females have greater severity and susceptibility to inflammatory disease (MacKenzie et al., 1979; Wilder et al., 1982; Allen et al., 1983; Deighton et al., 1992; Griffiths et al., 1994; Da Silva, 1995; Holmdahl, 1995; Katz and Criswell, 1996), we evaluated the role of the female sex steroid $17 \beta$-estradiol in BK-induced PE, an integral component of the inflammatory response. The observations that (1) gonadectomy in female rats resulted in an increase in BKinduced PE, whereas administration of $17 \beta$-estradiol to gonadectomized female rats reconstituted the female phenotype, and (2) castration in male rats resulted in a decrease in BK-induced PE, whereas administration of testosterone to castrated male rats reconstituted the male phenotype, strongly argues in favor of a major part of sex differences in this component of the inflammatory response being attributable to these sex steroids. Our work extends previous studies that have shown that sex steroids modulate inflammatory disease severity [e.g., estrogens enhance (Allen et al., 1983; Ansar Ahmed et al., 1985) and testosterone reduces severity of inflammatory disease in animal models (Da Silva et al., 1993a; Harbuz et al., 1995; Booji et al., 1996)] to provide a detailed analysis of the influence of sex and sex steroids on a critical component of the acute inflammatory response, BK-induced PE.

\section{Mechanisms of sex differences}

Analysis of the mechanism by which a major female sex steroid influences BK-induced PE leads us to hypothesize that the female sex steroid $17 \beta$-estradiol produces its effect on the inflammatory response via a sympathoadrenal axis-dependent mechanism, because adrenalectomy and adrenal denervation in female rats results in increased $\mathrm{BK}$-induced $\mathrm{PE}$, and estrogen receptor $\alpha$ immunoreactivity is present in adrenal medullary cells. That sympathoadrenal axis ablation did not affect BK-induced PE in males supports the suggestion that these surgical interventions did not have nonspecific effects on PE.
Sympathoadrenal axis. In the present study, we tested the hypothesis that sex steroid effects on BK-induced PE are mediated by an action on the sympathoadrenal axis. Although adrenalectomy in female rats changed the PE response induced by $\mathrm{BK}$ to make it like that of male rats, adrenalectomy also ablated the adrenal medulla component of the sympathoadrenal axis. Because the magnitude of BK-induced PE was similar after adrenal denervation and adrenalectomy, we suggest that an adrenal medullary factor(s) in females may be sufficient to account for the sex differences in BK-induced PE observed in this study. Furthermore, because adrenal denervation also blocks the effect of $17 \beta$ estradiol implants in gonadectomized females, this further supports the hypothesis that $17 \beta$-estradiol's effects are dependent on an intact sympathoadrenal axis. In contrast, the adrenal medulla does not appear to mediate male hormone modulation of BKinduced PE. Finally, the presence of estrogen receptor $\alpha$ immunoreactivity in female adrenal medullary cells supports the suggestion that the female sex steroid estrogen acts directly on the adrenal medulla to induce sympathoadrenal-dependent differences in inflammation.

There is a limited literature describing sex differences in the sympathetic activation of the adrenal medulla (Hinojosa-Laborde et al., 1999). For example, it is known that increases in plasma catecholamine in response to stress is much greater in female rats (Livezey et al., 1985; Taylor et al., 1989; Weinstock et al., 1998) and in women (Frankenhaeuser et al., 1976). Although the site of action of sex steroids on the sympathoadrenal system is unknown, and an action in the CNS cannot be excluded (Hinojosa-Laborde et al., 1999), the presence of estrogen receptor on female adrenal medullary cells provides support for the suggestion that these cells are the target for estrogen's action. Interestingly, the epinephrine and norepinephrine content of adrenal medullary cells varies with estrous cycle in female rats (de Miguel et al., 1989). Although this is the first report that the estrogen receptor is present in adrenomedullary cells, it has recently been reported that estrogen receptor protein and estrogen receptor mRNA are also present in closely related (Anderson, 1993; Lachmund et al., 1994) postganglionic sympathetic neurons (Papka et al., 1997). Despite the fact that the functional role for these receptors is yet to be determined, the observation that they are cytosolic rather than nuclear receptors suggests that they may mediate more rapid 


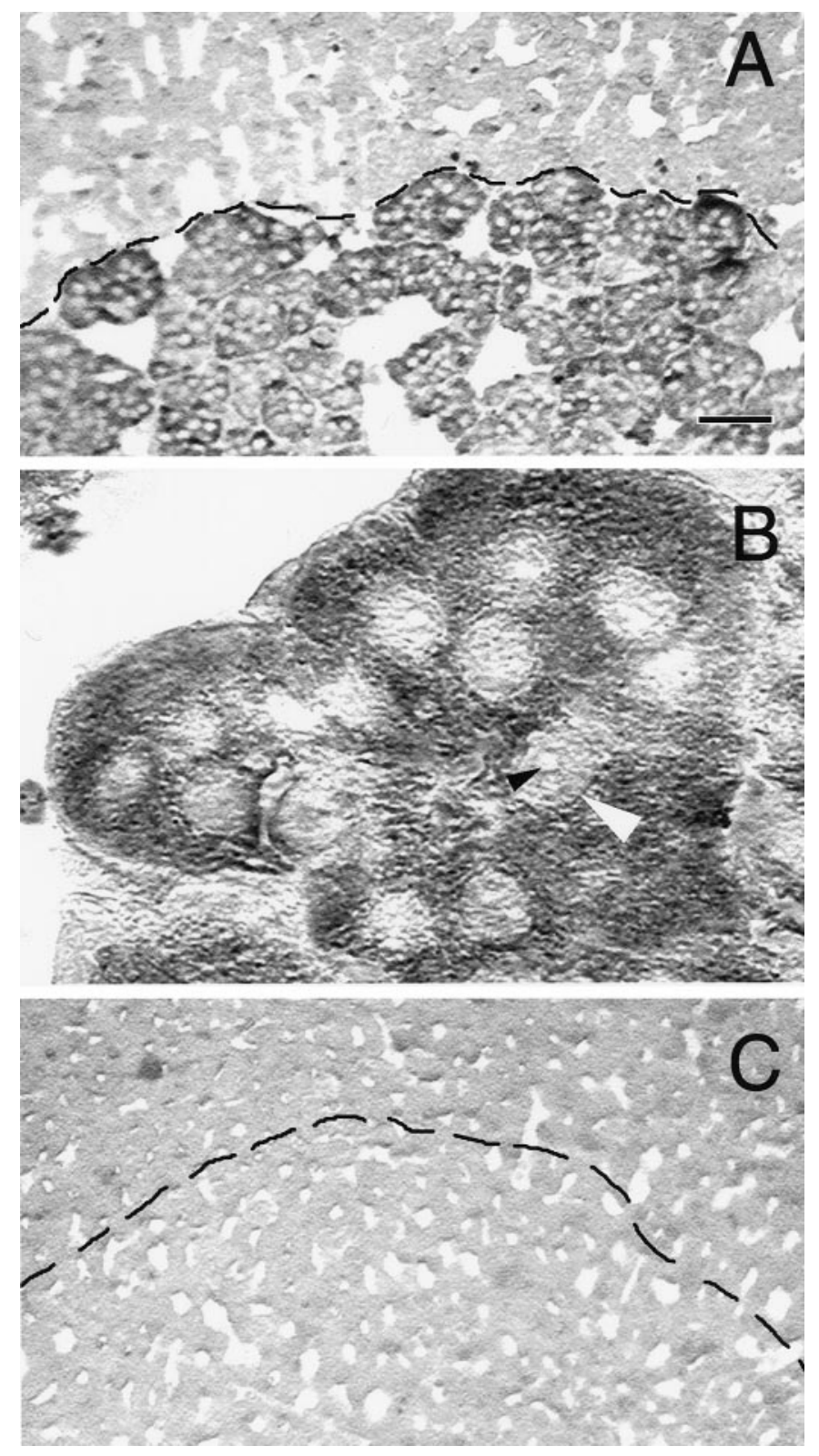

Figure 6. Estrogen receptor $\alpha$ immunohistochemistry. Light microscopy of a female rat adrenal gland immunolabeled with mouse monoclonal antibody to estrogen receptor $\alpha(A, B)$ or with negative control mouse IgG1 $(C)$; adrenal medulla has been set off by dashed lines. Cytoplasmic immunoreactivity to estrogen receptor $\alpha$ is apparent in the adrenal medullary cells. A syncitium of adrenal medullary cells is shown at higher magnification in $B$. In contrast to the cytoplasmic immunoperoxidase reaction product seen in these cells, the nucleus (white arrowhead) and nucleolus (black arrowhead) show little or no immunoreactivity. No immunoreactivity is evident in adrenal cortical cells or in cells incubated with control antibody. Scale bars: $A, C, 100 \mu \mathrm{m} ; B, 9 \mu \mathrm{m}$.

effects of estrogen, such as release of mediators (Wang et al., 1995; Gu and Moss, 1996), rather than estrogen-induced protein synthesis. The adrenal medulla releases several mediators that may affect the inflammatory response. For example, catecholamines (Coderre et al., 1991), enkephalins (Green and Levine, 1992), galanin (Green et al., 1992), neuropeptide Y (Green et al., 1993a), and corticotropin-releasing hormone (Wei et al., 1993) attenuate inflammatory mediator-induced PE. In particular, catecholamines and neuropeptide Y may be released during stress to produce plasma levels that are vasoconstrictive (Zukowska-Grojec, 1995), and we have provided evidence that they potently inhibit BK-induced PE in the knee joint (Green et al., 1993b). Finally, our results support the suggestion that the sympathoadrenal axis may play an important role in gender differences in stress physiology.

HPA axis. Because sexual dimorphism is well established in the HPA axis (Patchev and Almeida, 1998) and the HPA axis regulates inflammation (Da Silva et al., 1993b; Da Silva, 1995; Masi et al., 1996), we tested the hypothesis that the sex difference we observed in BK-induced PE may be mediated, at least in part, by the HPA axis. However, we found that the HPA axis did not appear to play a role in sex differences because hypophysectomy did not affect the magnitude of BK-induced PE in females or males. Thus, sex differences in glucocorticoid physiology are also unlikely to mediate these effects [although estrogen enhances glucocorticoid release (Amin et al., 1980) and BK-induced PE is inhibited by noxious stimulation-induced release of glucocorticoid from the adrenal gland (Green et al., 1997)], because inhibition of corticosteroid synthesis with metyrapone had no effect on the magnitude of BK-induced PE in female or male rats. Interestingly, $>90 \%$ of rheumatoid arthritis patients do not show abnormality in cortisol levels, suggesting a normally functioning HPA axis (Wilder, 1995); however, it is important to note that there are species differences in the role sex steroids play in the severity of arthritis (Wilder, 1996). Thus, it is still possible that the HPA axis regulates other elements of the inflammatory response in a gender-dependent manner (Da Silva et al., 1993b; Da Silva, 1995; Masi et al., 1996).

Hypophysectomy also decreases plasma levels of sex steroids, which might be expected to influence PE levels; however, it should be noted that PE studies were performed only 7-10 d after hypophysectomy, in contrast to ovariectomies, which were performed $\sim 10$ weeks before PE studies. Because of large sex steroid stores in fatty tissue (Deslypere et al., 1985), their continued synthesis in corpus lutea (albeit at a reduced rate) for at least 4 weeks after hypophysectomy (Halling, 1992) and the number of weeks required for altered gene expression to be manifested on removal of estrogens [e.g., rat brain 5-hydroxytryptamine $2 \mathrm{~A}$ receptor densities are decreased 3 months but not 2 weeks after ovariectomy (Cyr et al., 1998)], it is not surprising that we failed to observe an effect on PE 1 week after hypophysectomy.

\section{Chronic inflammatory disease severity}

Although the etiology of inflammatory diseases such as rheumatoid arthritis are not known, the pathogenetic mechanisms are believed, at least in part, to be immunologically determined; therefore, sex differences in inflammatory response are usually ascribed to an action on the immune system (Ansar Ahmed et al., 1985). In addition, in both female and male rheumatoid arthritis patients, gonadal and adrenal androgens (testosterone and dihydrotestosterone) are suppressed, and androgen administration appears to be protective in chronic inflammatory disease in both animal models and clinical trials (for review, see Lahita, 1996). Rheumatoid arthritis and other rheumatic diseases are more severe in females, yet estrogen produces a decrease in PE. Although this may appear paradoxical, we have shown that mediators that decrease BK-induced PE increase the radiological severity of adjuvant-induced arthritis, and mediators that increase BK-induced PE decrease the radiological severity of adjuvantinduced arthritis (Coderre et al., 1991; Green et al., 1991; Miao et al., 1992b). This has led to the suggestion that PE may be a tissue 
protective or reparative component of the synovial inflammatory response (Basbaum and Levine, 1991).

In summary, we have shown that there are sex differences in the PE component of the inflammatory response in rats and that this is dependent on sex steroids in both female and male animals. Importantly, we have shown in female rats a sympathoadrenal axis dependence. Further experiments are required to determine whether estrogen acts at the level of the adrenal medullary cell, which sympathoadrenal mediators contribute to the sex differences in the inflammatory response, and whether the sympathoadrenal axis also contributes to sex differences in chronic inflammatory disease models.

\section{REFERENCES}

Akana SF, Cascio CS, Shinsako J, Dallman MF (1985) Corticosterone: narrow range required for normal body and thymus weight and ACTH. Am J Physiol 249:R527-532.

Allen JB, Blatter D, Calandra GB, Wilder RL (1983) Sex hormonal effects on the severity of streptococcal cell wall-induced polyarthritis in the rat. Arthritis Rheum 26:560-563.

Amin ES, El Sayed MM, El Gamel BA, Nayel SA (1980) Comparative study of the effect of oral contraceptives containing 50 microgram of estrogen and those containing 20 microgram of estrogen on adrenal cortical function. Am J Obstet Gynecol 137:831-833.

Anderson DJ (1993) Cell fate determination in the peripheral nervous system: the sympathoadrenal progenitor. J Neurobiol 24:185-198.

Ansar Ahmed S, Penhale WJ, Talal N (1985) Sex hormones, immune responses, and autoimmune diseases. Mechanisms of sex hormone action. Am J Pathol 121:531-551.

Basbaum AI, Levine JD (1991) The contribution of the nervous system to inflammation and inflammatory disease. Can J Physiol Pharmacol 69:647-651.

Booji A, Biewenga-Booji CM, Huber-Bruning O, Cornelis C, Jacobs JW, Bijlsma JW (1996) Androgens as adjuvant treatment in postmenopausal female patients with rheumatoid arthritis. Ann Rheum Dis 55:811-815.

Bridges RS (1984) A quantitative analysis of the roles of dosage, sequence, and duration of estradiol and progesterone exposure in the regulation of maternal behavior in the rat. Endocrinology 114:930-940.

Bridges RS, Russell DW (1981) Steroidal interactions in the regulation of maternal behaviour in virgin female rats: effects of testosterone, dihydrotestosterone, oestradiol, progesterone and the aromatase inhibitor, 1,4,6-androstatriene-3,17-dione. J Endocrinol 90:31-40.

Calogero AE, Sternberg EM, Bagdy G, Smith C, Bernardini R, Aksentijevich S, Wilder RL, Gold PW, Chrousos GP (1992) Neurotransmitterinduced hypothalamic-pituitary-adrenal axis responsiveness is defective in inflammatory disease-susceptible Lewis rats: in vivo and in vitro studies suggesting globally defective hypothalamic secretion of corticotropin-releasing hormone. Neuroendocrinology 55:600-608.

Carr J, Wilhelm DL (1964) The evaluation of increased vascular permeability in the skin of guinea pigs. Aust J Exp Biol Med Sci 42:511-522.

Celler BG, Schramm LP (1981) Pre- and postganglionic sympathetic activity in splanchnic nerves of rats. Am J Physiol 241:R55-R61.

Coderre TJ, Basbaum AI, Levine JD (1989) Neural control of vascular permeability: interactions between primary afferents, mast cells, and sympathetic efferents. J Neurophysiol 62:48-58.

Coderre TJ, Basbaum AI, Dallman MF, Helms C, Levine JD (1990) Epinephrine exacerbates arthritis by an action at presynaptic $\beta_{2}$ adrenoceptors. Neuroscience 34:521-523.

Coderre TJ, Chan AK, Helms C, Basbaum AI, Levine JD (1991) Increasing sympathetic nerve terminal-dependent plasa extravasation correlates with decreased arthritic joint injury in rats. Neuroscience 40:185-189.

Cyr M, Bosse R, Di Paolo T (1998) Gonadal hormones modulate 5-hydroxytryptamine $2 \mathrm{~A}$ receptors: emphasis on the rat frontal cortex. Neuroscience 83:829-836.

Da Silva JA (1995) Sex hormones, glucocorticoids and autoimmunity: facts and hypotheses. Ann Rheum Dis 54:6-16.

Da Silva JA, Larbre JP, Spector TD, Perry LA, Scott DL, Willoughby DA (1993a) Protective effect of androgens against inflammation induced cartilage degradation in male rodents. Ann Rheum Dis 52:285-291.
Da Silva JA, Peers SH, Perretti M, Willoughby DA (1993b) Sex steroids affect glucocorticoid response to chronic inflammation and to interleukin-1. J Endocrinol 136:389-397.

Da Silva JA, Larbre JP, Seed MP, Cutolo M, Villaggio B, Scott DL, Willoughby DA (1994) Sex differences in inflammation induced cartilage damage in rodents. The influence of sex steroids. J Rheumatol 21:330-337.

de Miguel R, Fernandez-Ruiz JJ, Hernandez ML, Ramos JA (1989) Role of ovarian steroids on the catecholamine synthesis and release in female rat adrenal: in vivo and in vitro studies. Life Sci 44:1979-1986.

Deighton CM, Surtees D, Walker DJ (1992) Influence of the severity of rheumatoid arthritis on sex differences in health assessment questionnaire scores. Ann Rheum Dis 51:473-475.

Del Rio G, Carani C, Velardo A, Zizzo G, Procopio M, Coletta F, Marrama P, Ghigo E (1995) Effect of testosterone replacement therapy on the somatotrope responsiveness to GHRH alone or combined with pyridostigmine and on sympathoadrenal activity in patients with hypogonadism. J Endocrinol Invest 18:690-695.

Deslypere JP, Verdonck L, Vermeulen A (1985) Fat tissue: a steroid reservoir and site of steroid metabolism. J Clin Endocrinol Metab 61:564-570.

DeTurck KH, Vogel WH (1980) Factors influencing plasma catecholamine levels in rats during immobilization. Pharmacol Biochem Behav 13:129-131.

Ehlers CL, Kaneko WM, Owens MJ, Nemeroff CB (1993) Effects of gender and social isolation on electroencephalogram and neuroendocrine parameters in rats. Biol Psychiatry 33:358-366.

Fisher RA (1949) The design of experiments. Edinburgh: Oliver and Boyd Ltd.

Frankenhaeuser M, Dunne E, Lundberg U (1976) Sex differences in sympathetic-adrenal medullary reactions induced by different stressors. Psychopharmacology (Berl) 47:1-5.

Greco B, Edwards DA, Michael RP, Clancy AN (1998) Androgen receptors and estrogen receptors are colocalized in male rat hypothalamic and limbic neurons that express Fos immunoreactivity induced by mating. Neuroendocrinology 67:18-28.

Green PG, Levine JD (1992) $\delta$ - and $\kappa$-opioid agonists inhibit plasma extravasation induced by bradykinin in the knee joint of the rat. Neuroscience 49:129-133.

Green PG, Basbaum AI, Helms C, Levine JD (1991) Purinergic regulation of bradykinin-induced plasma extravasation and adjuvant-induced arthritis in the rat. Proc Natl Acad Sci USA 88:4162-4165.

Green PG, Basbaum AI, Levine JD (1992) Sensory neuropeptide interactions in the production of plasma extravasation in the rat. Neuroscience 50:745-749.

Green PG, Luo J, Heller PH, Levine JD (1993a) Modulation of bradykinin-induced plasma extravasation in the rat knee joint by sympathetic co-transmitters. Neuroscience 52:451-458.

Green PG, Luo J, Heller PH, Levine JD (1993b) Neurogenic and nonneurogenic mechanisms of plasma extravasation in the rat. Neuroscience 52:735-743.

Green PG, Miao FJ, Jänig W, Levine JD (1995) Negative feedback neuroendocrine control of the inflammatory response in rats. J Neurosci 15:4678-4686.

Green PG, Jänig W, Levine JD (1997) Negative feedback neuroendocrine control of inflammatory response in the rat is dependent on the sympathetic postganglionic neuron. J Neurosci 17:3234-3238.

Griffiths MM, Sawitzke AD, Harper DS, McCall S, Reese VR, Cannon GW (1994) Exacerbation of collagen-induced arthritis in rats by rat cytomegalovirus is antigen-specific. Autoimmunity 18:177-187.

Gu Q, Moss RL (1996) 17 $\beta$-Estradiol potentiates kainate-induced currents via activation of the cAMP cascade. J Neurosci 16:3620-3629.

Halling A (1992) Steroid synthesis in ovarian homogenates from hypophysectomized adult female mice treated with diethylstilbestrol in neonatal life. J Toxicol Environ Health 36:341-353.

Handa RJ, Burgess LH, Kerr JE, O’Keefe JA (1994) Gonadal steroid hormone receptors and sex differences in the hypothalamo-pituitaryadrenal axis. Horm Behav 28:464-476.

Harbuz MS, Perveen-Gill Z, Lightman SL, Jessop DS (1995) A protective role for testosterone in adjuvant-induced arthritis. Br J Rheumatol 34:1117-1122.

Hinojosa-Laborde C, Chapa I, Lange D, Haywood JR (1999) Gender differences in sympathetic nervous system regulation. Clin Exp Pharmacol Physiol 26:122-126. 
Holmdahl R (1995) Female preponderance for development of arthritis in rats is influenced by both sex chromosomes and sex steroids. Scand J Immunol 42:104-109.

Jemec GB, Heidenheim M (1995) The influence of sex hormones on UVB induced erythema in man. J Dermatol Sci 9:221-224.

Josefsson E, Tarkowski A (1997) Suppression of type II collageninduced arthritis by the endogenous estrogen metabolite 2-methoxyestradiol. Arthritis Rheum 40:154-163.

Katz PP, Criswell LA (1996) Differences in symptom reports between men and women with rheumatoid arthritis. Arthritis Care Res 9:441-448.

Kennedy J, Baris C, Hoyland JA, Selby PL, Freemont AJ, Braidman IP (1999) Immunofluorescent localization of estrogen receptor-alpha in growth plates of rabbits, but not in rats, at sexual maturity. Bone 24:9-16.

Kirschbaum C, Schommer N, Federenko I, Gaab J, Neumann O, Oellers M, Rohleder N, Untiedt A, Hanker J, Pirke KM, Hellhammer DH (1996) Short-term estradiol treatment enhances pituitary-adrenal axis and sympathetic responses to psychosocial stress in healthy young men. J Clin Endocrinol Metab 81:3639-3643.

Kitay JI (1961) Sex differences in adrenal cortical secretion in the rat. Endocrinology 68:818-824.

Kozik A, Moore RB, Potempa J, Imamura T, Rapala-Kozik M, Travis J (1998) A novel mechanism for bradykinin production at inflammatory sites. Diverse effects of a mixture of neutrophil elastase and mast cell tryptase versus tissue and plasma kallikreins on native and oxidized kininogens. J Biol Chem 273:33224-33229.

Lachmund A, Gehrke D, Krieglstein K, Unsicker K (1994) Trophic factors from chromaffin granules promote survival of peripheral and central nervous system neurons. Neuroscience 62:361-370.

Lahita RG (1996) The connective tissue diseases and the overall influence of gender. Int J Fertil Menopausal Stud 41:156-165.

Le Thu L, Eremina SA, Chernositov AV, Sukhov AG, Beliakova EI (1984) Electrophysiological and catecholamine mechanisms of negative feedback in regulation of the hypothalamus by male sex glands. Biull Eksp Biol Med 97:722-725.

Livezey GT, Miller JM, Vogel WH (1985) Plasma norepinephrine, epinephrine and corticosterone stress responses to restraint in individual male and female rats, and their correlations. Neurosci Lett 62:51-56.

Lundeberg T, Nordling L, Liedberg H, Theodorsson E, Ekman P (1993) Epinephrine reduces the severity of catheter-induced urethral inflammation by action at the alpha 2-adrenoceptors. Br J Urol 72:349-352.

MacKenzie AR, Sibley PR, White BP (1979) Resistance and susceptibility to the induction of rat adjuvant disease. Diverging susceptibility and severity achieved by selective breeding. Br J Exp Pathol 60:507-512.

Masi AT, Da Silva JA, Cutolo M (1996) Perturbations of hypothalamicpituitary-gonadal (HPG) axis and adrenal androgen (AA) functions in rheumatoid arthritis. Baillieres Clin Rheumatol 10:295-332.

Miao FJ-P, Benowitz NL, Basbaum AI, Levine JD (1992a) Sympathoadrenal contribution to nicotinic and muscarinic modulation of bradykinin-induced plasma extravasation in the knee joint of the rat. J Pharmacol Exp Ther 262:889-895.

Miao FJ-P, Helms C, Benowitz NL, Basbaum AI, Heller PH, Levine JD (1992b) Chronically administered nicotine attenuates bradykinininduced plasma extravasation and aggravates arthritis-induced joint injury in the rat. Neuroscience 51:649-655.
Ng AV, Callister R, Johnson DG, Seals DR (1993) Age and gender influence muscle sympathetic nerve activity at rest in healthy humans. Hypertension 21:498-503.

Papka RE, Srinivasan B, Miller KE, Hayashi S (1997) Localization of estrogen receptor protein and estrogen receptor messenger RNA in peripheral autonomic and sensory neurons. Neuroscience 79:1153-1163.

Patchev VK, Almeida OF (1998) Gender specificity in the neural regulation of the response to stress: new leads from classical paradigms. Mol Neurobiol 16:63-77.

Peskind ER, Raskind MA, Wingerson D, Pascualy M, Thal LJ, Dobie DJ, Veith RC, Dorsa DM, Murray S, Sikkema C, Galt SA, Wilkinson CW (1995) Enhanced hypothalamic-pituitary-adrenocortical axis responses to physostigmine in normal aging. J Gerontol A Biol Sci Med Sci 50:M114-120.

Smith ER, Damassa DA, Davidson JM (1977) Hormone administration: peripheral and intracranial implants. In: Methods in psychobiology (Myers RD, ed), pp 259-279. New York: Academic.

Sternberg EM, Hill JM, Chrousos GP, Kamilaris T, Listwak SJ, Gold PW, Wilder RL (1989) Inflammatory mediator-induced hypothalamicpituitary-adrenal axis activation is defective in streptococcal cell wall arthritis-susceptible Lewis rats. Proc Natl Acad Sci USA 86:2374-2378.

Suescun M, Chisari AN, Carino M, Hadid R, Gaillard RC, Spinedi E (1994) Sex steroid regulation of the hypothalamo-pituitary-adrenal axis activity in middle-aged mice during endotoxic shock. Neuroimmunomodulation 1:315-320.

Sweep F, Rijnkels C, Hermus A (1991) Activation of the hypothalamuspituitary-adrenal axis by cytokines. Acta Endocrinol (Copenh) 125[Suppl 1]:84-91.

Taylor J, Weyers P, Harris N, Vogel WH (1989) The plasma catecholamine stress response is characteristic for a given animal over a oneyear period. Physiol Behav 46:853-856.

Wang H, Ward AR, Morris JF (1995) Oestradiol acutely stimulates exocytosis of oxytocin and vasopressin from dendrites and somata of hypothalamic magnocellular neurons. Neuroscience 68:1179-1188.

Waynforth HB, Flecknell PA (1992) Experimental and surgical technique in the rat. London: Academic.

Wei ET, Gao GC, Thomas HA (1993) Peripheral anti-inflammatory actions of corticotropin-releasing factor. Ciba Found Symp 172:258-268.

Weinstock M, Razin M, Schorer-Apelbaum D, Men D, McCarty R (1998) Gender differences in sympathoadrenal activity in rats at rest and in response to footshock stress. Int J Dev Neurosci 16:289-295.

Weyand CM, Schmidt D, Wagner U, Goronzy JJ (1998) The influence of sex on the phenotype of rheumatoid arthritis. Arthritis Rheum 41:817-822.

Wilder RL (1995) Neuroendocrine-immune system interactions and autoimmunity. Annu Rev Immunol 13:307-338.

Wilder RL (1996) Hormones and autoimmunity: animal models of arthritis. Baillieres Clin Rheumatol 10:259-271.

Wilder RL, Calandra GB, Garvin AJ, Wright KD, Hansen CT (1982) Strain and sex variation in the susceptibility to streptococcal cell wallinduced polyarthritis in the rat. Arthritis Rheum 25:1064-1072.

Zukowska-Grojec Z (1995) Neuropeptide Y. A novel sympathetic stress hormone and more. Ann NY Acad Sci 771:219-233. 